\title{
A new ice sheet model validated by remote sensing of the Greenland ice sheet
}

Research Article

\author{
Diandong Ren ${ }^{1 *}$, Rong Fu ${ }^{1}$, David J. Karoly², Lance M. Leslie ${ }^{3,5}$, Jianli Chen ${ }^{4}$, Clark R. Wilson ${ }^{1,4}$ \\ 1 Jackson School of Geosciences, \\ The University of Texas at Austin, USA \\ 2 School of Earth Sciences, \\ University of Melbourne, Australia \\ 3 School of Meteorology, \\ University of Oklahoma, Norman, Oklahoma, USA \\ 4 Center for Space Research, \\ The University of Texas at Austin, USA \\ 5 Australian Sustainable Development Institute, \\ Curtin University, Perth, Australia
}

Received 21 March 2010; accepted 1 June 2010

\begin{abstract}
Accurate prediction of future sea level rise requires models that accurately reproduce and explain the recent observed dramatic ice sheet behaviours. This study presents a new multi-phase, multiple-rheology, scalable and extensible geofluid model of the Greenland ice sheet that shows the credential of successfully reproducing the mass loss rate derived from the Gravity Recovery and Climate Experiment (GRACE), and the microwave remote sensed surface melt area over the past decade. Model simulated early 21 st century surface ice flow compares satisfactorily with InSAR measurements. Accurate simulation of the three metrics simultaneously cannot be explained by fortunate model tuning and give us confidence in using this modelling system for projection of the future fate of Greenland Ice Sheet (GrIS). Based on this fully adaptable three dimensional, thermo-mechanically coupled prognostic ice model, we examined the flow sensitivity to granular basal sliding, and further identified that this leads to a positive feedback contributing to enhanced mass loss in a future warming climate. The rheological properties of ice depend sensitively on its temperature, thus we further verified modelâ€Źs temperature solver against in situ observations. Driven by the NCEP/NCAR reanalysis atmospheric parameters, the ice model simulated GrIS mass loss rate compares favourably with that derived from the GRACE measurements, or about $-147 \mathrm{~km}^{3} / \mathrm{yr}$ over the $2002-2008$ period. Increase of the summer maximum melt area extent (SME) is indicative of expansion of the ablation zone. The modeled SME from year 1979 to 2006 compares well with the cross-polarized gradient ratio method (XPGR) observed melt area in terms of annual variabilities. A high correlation of 0.88 is found between the two time series. In the 30 -year model simulation series, the surface melt exhibited large inter-annual and decadal variability, years 2002, 2005 and 2007 being three significant recent melt episodes.
\end{abstract}

Keywords: Greenland ice sheet modeling • ice thermodynamics and dynamics• granular rheology $\cdot$ climate change and feedbacks $\cdot$ cryosphere processes - remote sensing of ice sheet

(C) Versita Warsaw 


\section{Introduction}

Because of its size ( $8 \%$ of Earth's total ice) and unique location (close to ocean deep convection sites associated with the oceanic meridional overturning circulation), the Greenland Ice Sheet (GrlS) is an important factor in eustatic sea level rise, ocean salinity and the North Atlantic thermohaline circulation [1-3]. Its response to a warming climate and its influence on global and regional climate has been widely acknowledged [4,5]. There has been considerable progress in GrlS research, primarily from remote sensing techniques that generate high-resolution ice sheet geometry data [6], surface melt conditions [7], and surface flow fields [8]. Ice core drilling efforts [9] have contributed significantly. Recent surveys $[10,11]$ reveal increased flow speeds, widespread melting of the ice surface and accelerating mass loss from peripheral outlet glaciers. Consequently, the ice mass loss has accelerated in the last decade, and previous ice flow speeds are likely to be significant underestimates.

Global warming is estimated at $0.6^{\circ} \mathrm{C}$ over the past thirty years and $0.8^{\circ} \mathrm{C}$ in the past century [12]. The IPCC Fourth Assessment Report [13] (http://ipcc-wg1.ucar.edu/wg1/ wg1-report.html) concluded that most of the global-scale warming over the last fifty years is very likely due to increased greenhouse gas concentrations. The warming trend is significant in climate model simulations under various future scenarios, and the fate of the cryosphere is of great concern $[14,15]$. Considering the rapid global warming from the 1970s and the even larger manifestations over the Arctic region, due to possible polar amplifications, the reported enhanced melting may be just the beginning. Ice core data from the summit of the GrIS indicate that temperature and accumulation rates can increase significantly over periods ranging from a few years to decades [16]. Large natural variability signals over the region confirm that the surveyed periods (e.g., 1995-2005) provide a limited temporal perspective, and are too brief to answer a longstanding concern: will this net mass loss trend continue in the future so that the contribution of GrlS melting to global sea-level rise continues to increase?

"A measure of our understanding is our ability to predict" is appropriate for studying GrIS mass balance and its contribution to sea level rise (R. Bindschadler, personal communication 2009). The accurate prediction of future seal level risees requires ice models that have the skill to reproduce and explain the recent and dramatic ice sheet behaviours seen. Unfortunately, many current ice models do not capture observed ice sheet behaviour (IPCC AR4) because they have simplified the fundamental physics in the model, such as the treatment of basal and lateral boundary conditions. The IPCC AR4 thus used only a surface- mass-balance estimation in sea-level predictions, stating that "quantitative projections of how much the accelerated ice flow would add (to sea level rise) cannot be made with confidence, owing to limited understanding of the relevant processes (Subsection 5.1 of [13])."

On the other hand, model projection of the ice sheet contribution to sea level change is facilitated by new technologies that have resulted in a significant increase in the observational properties of the ice sheet [17]. Here we introduce a new modelling system with improved basal sliding physics, advanced computational treatment of higher order terms, and a fully-fledged data assimilation capacity. Different from many previous ice dynamics models, which are based upon the assumption that the ice sheet is locally in equilibrium and thus omit many so-called higher-order terms, our model keeps the full form of the Navier-Stokes equation. Another crucial new feature of our ice dynamics model is applying a granular sliding layer between the bottom ice layer and the lithosphere layer. The idea was inspired by recent developments in granular material rheology [18] and because a lubricating layer of basal sediments present between the ice and the bedrock enhances ice flow and is a mechanism for large scale surgees $[19,20]$ in a warming future world. The modelling system is validated using remote sensing measurements of the GrlS.

\section{Data}

Idealized geometrical configurations are used in explaining mechanisms in the model. However, the most rigorous verification of the model is found by comparing the model data against real GrIS properties. The following data sets are required to input into the model simulation and compare it to the observed GrIS features of the $20^{\text {th }}$ and early $21^{\text {st }}$ century.

\subsection{Digital elevation map, geothermal heat flux, and initial ice temperature field}

The ice model requires for input the ice thickness and free surface elevation. A $5 \mathrm{~km}$ digital elevation map (DEM) for bedrock and ice thickness data [6] is available for the whole of Greenland from the Sea-level Response to Ice Sheet Evolution (SeaRISE) project website (http://websrv.cs.umt.edu/isis/index.php). The total ice volume is $\sim 2.9 \times 10^{6} \mathrm{~km}^{3}$.

Due to the low heat conductivity of ice $\left(2.07 \mathrm{~W} \mathrm{~m}^{-1} \mathrm{~K}^{-1}\right.$ at $0^{\circ} \mathrm{C}$ ), effects from an erroneous initial temperature profile persist. Unfortunately, in situ measurements of ice temperature profiles are very limited over Greenland. There- 
fore the initial temperature field is sourced from a paleoclimate simulation of the SImulation COde for POLythermal Ice Sheets (SICOPOLIS [21]), covering the entire last glacial-interglacial cycle (150 kyr BP-modern, [22]). Since the existing temperature field is of $20 \mathrm{~km}$ resolution, a $5 \mathrm{~km}$ resolution with a bi-linear scheme is interpolated. The ice sheet temperature regime is controlled by the surface energy balance history, ice flow, and the spatial distribution of geothermal heat flux [22-24]. For future simulations, the geothermal pattern is taken as constant, as in the hf_pmod2 experiment of [22], because it provides realistic modern GrIS geometry and flow fields.

\subsection{NCEP/NCAR re-analysis data}

Coupled ocean-atmospheric climate models (CGCMs) do not resolve realistic phases for inter-annual and decadal climate variations. Thus, they cannot be used as climate forcing for ice model validation against observations on these scales. More realistic climate forcing provided by the National Center for Environmental Prediction (NCEP)/NCAR re-analysis is used (http://www.cdc.noaa.gov/data/gridded/data. ncep.reanalysis.derived.surfaceflux.html). The $20^{\text {th }}$ century simulations of the GCMs (20C3M runs in CMIP terminology) are used to initialize the model first, then to blend in atmospheric parameters from the NCEP/NCAR reanalysis data. Specifically, the 20C3M monthly output is used from two recently available high-resolution CGCMs (i.e., MIROC3.2-hires [K-1 Model Developers 2004] and NCAR-CCSM3 [25]) to spin-up the ice model. The 19482008 atmospheric parameters provided by CGCMs are then replaced with the NCEP/NCAR re-analysis data of monthly mean precipitation, surface air temperature, and surface energy fluxes. Because the time period of the re-analysis data (1948-present) incorporates the satellite era (1979-present), ice dynamics models forced or driven by this time series should reproduce the remotely sensed recent changes of the GrIS.

\section{Ice dynamics model}

The new numerical model is a continuum-mechanical formulation. The stress decomposition of Van der Veen and Whillans [26] is followed. In ice flow, inertial and viscous terms counteract the pressure gradient force (pgf). The model includes the full form of the Navier-Stokes equation [27]. Thermodynamic aspects of the model follow primarily the SICOPOLIS [21] model, including its 'front-tracking' way of handling phase changes. That a dynamic/thermodynamic model for a whole ice sheet must include both horizontal and vertical advection is broadly agreed upon because the scalar quantities (e.g., temperature and viscosity enhancement factors) in an ice sheet are usually non-uniform and can be redistributed by the flow. In fact, the temperature field in an ice sheet is largely controlled by advection, except for near a summit, where only vertical advection acts. There is little consensus concerning using the full form of the Navier-Stokes equation in model simulations. It is numerically demanding and relatively time-consuming compared to shallow ice models, which assume a balance of viscous and the pgf. For temperate valley glaciers of large aspect ratio, residing on steep bedrock or partially submerged under water, and those with particular thermodynamic conditions, it seems necessary to keep the full Stokes equation [28]. At the GrIS margins, fast-flowing ice streams discharge huge amounts of ice into the ocean. A full Navier-Stokes model may thus be superior in simulating the ice stream and the surrounding transition zones because of their large aspect ratios.

The thermo-mechanically coupled scheme is now designed and implemented as one integral component of a scalable and extensible geofluid model (SEGMENT), here termed SEGMENT-ice. This model provides prognostic fields of the driving and resistive forces and describes the flow fields and dynamic evolution of thickness profiles through the ice. The governing dynamic and thermodynamic equations, together with the flow chart, can be found in the Appendix.

Bueler and Brown [29] discuss in great detail a fully adaptable three dimensional, thermomechanically coupled, prognostic ice model [30]. This publication is of great benefit to the modelling community, and allows the current study to focus on where SEGMENT-ice differs from PISM.

Bueler and Brown [29], Engelhardt and Kamb [30], and Greve and Blatter [1] all point out the importance of a basal sliding mechanism in ice sheet dynamics. A Weertman-type sliding law [31], with overburden pressure corrected for sub-glacial water buoyancy, appears wellsuited for describing large-scale flow features (see Bindschadler, [32]). We follow the treatment of the basal sliding coefficient $C_{b}$ in the SICOPOLIS (Otsu, personal communication 2006). The crevasses distribution [33] may signify an important mechanism for surface melt water drainage. However, owing to a lack of survey data and large uncertainties in their distribution characteristics, it is difficult to directly parameterize their effects on basal sliding. Therefore, we follow an empirical approach, which uses a surface melt water coefficient, $\gamma$, usually between 0 to $6 \mathrm{yr} \mathrm{m}^{-1}$, to enhance $C_{b}$, using the linear multiplier $(1+\gamma m)$, with $m$ being the melt rate. The very existence of crevasses is a 
strong indication of uneven basal erosion, which produces granular material. The activation of the granular sliding mechanism is contingent upon the Weertman sliding.

Unlike ice, the viscosity of granular material depends also on the isotropic stress. For this granular sub-layer, a newly proposed rheology [8] is applied, namely,

$$
v=\left(\mu_{0}+\frac{\mu_{1}-\mu_{0}}{l_{0} / I+1}\right) \frac{S}{\left|\dot{\varepsilon_{e}}\right|}
$$

where $v$ is viscosity, $S=\left(R_{k k}-\rho g(h-z)\right) / 3$ is the spherical part of the stress tensor $\sigma, \mu_{0}$ and $\mu_{1}$ are the limiting values for the friction coefficient $\mu,\left|\dot{\varepsilon}_{e}\right|$ is the effective strain rate and $\left|\dot{\varepsilon}_{e}\right|=\left(0.5 * \dot{\varepsilon}_{i j} \cdot \dot{\varepsilon}_{i j}\right)^{0.5}, I_{0}$ is a constant depending on the local slope of the footing bed as well as the material properties, and $I$ is the inertial number defined as $I=\left|\dot{\varepsilon}_{e}\right| d /\left(S / \rho_{s}\right)^{0.5}$, where $d$ is the particle diameter and $\rho_{s}$ is the particle density. The granular layer thickness, basal material density, and the effective particle size are determined using the datum period 19001950: flow and mass are assumed in near balance. These parameters are thus spatially variable. For example, the effective grain size varies from $\sim 1 \mathrm{~mm}$ under the North east ice stream to $>20 \mathrm{~mm}$ underneath the Jakobshaven ice stream. All else being equal, the thickness of the granular material is somewhat proportional to the overlain ice thickness. Like most current ice dynamic models, our modelling framework supports Glen [34], Goldsby and Kohlstedt [35], and Durham's [36] flow laws.

Ice sheet mass balance is simply the difference between whatever goes in and whatever comes out. For a specific location, there are two factors that contribute to mass fluctuation: flow divergence/convergence and boundary mass fluxes. For the net mass balance of the ice sheet, arguably the most important quantity is the runoff. We adapted a runoff scheme from the Simulator for Hydrology and Energy Exchange at the Land Surface (SHEELS) [38]. In addition to 2D topography, Benson's [39] zone mask is also referred to. Assuming that all glacial melt water is not lost [40], neither is all precipitation assumed to be factored as net accumulation. Rainfall events can occur throughout the year whereas snowmelt storms are confined to the spring-summer months of each year. Therefore, we assume no change in mass for snow falling on the dry snow zone and percolation zone [39]. Melting water from the ablation zone is assumed to be lost in a manner analogous to water drainage from a porous sandy soil. This also applies to other cases that involve water redistribution among grids. The purpose of a carefully edited digital mask (the zones-division in Benson [39]) is to investigate the re-freezing of melt water and hence to gain an improved estimation of the net runoff. Because the form of precipitation under a warming climate may not strictly follow this mask, we assign a higher weighting to the surface temperature to thus determine the precipitation forms. For rainfall in the ablation zone, an important mixing process is included (namely, the $Q_{m}$ term in Equation 1 of Ren et al. [14]; Oerlemans [41]), because heat transferred to snow by rain during its cooling to $0^{\circ} \mathrm{C}$ is significant [42].

The precipitation and surface melt diagnosed by the runoff mechanism is the upper boundary condition for the continuity equation. Similarly, we apply zero-stress lateral boundary conditions for the momentum equation and apply surface energy balance as the upper boundary forcing for the thermodynamic equation. The lower boundary geothermal heating is equated in the same way as in SICOPOLIS. Atmospheric parameters are down-scaled to spatially match the ice geometry data in order to integrate the ice dynamics model at a $5 \mathrm{~km}$ resolution. 81 vertically stretched layers are used to delineate the ice thickness, including a lithosphere layer at the bottom, and an adjacent granular layer immediately above it. Because the temperature fluctuations are highest near the upper surface, whereas the largest flow shears are usually near the bottom, the vertical layers are finer near the upper and lower boundaries but coarser in between, according to a hyperbolic tangent stretching. The time step of integration is one day, with atmospheric forcing updated every month. This temporal configuration allows an examination of the surface melting extent, as for most of the surface area melting is seasonal. With an annual time step, as in most paleoclimate studies, it is impossible to resolve this dynamic feature of the melt surface area, which is a sensitive index of climate warming. The bedrock is given a viscosity of $8 \times 10^{20} \mathrm{~Pa} \cdot \mathrm{s}$, close to the values for upper mantle material.

A finite differences technique is used to seperate the governing equations. The SEGMENT-ice uses a staggered Arakawa C-grid stencil so that mass (and other scalar variables such as temperature) and velocity components are interlaced. The vertical grid is terrain following $\sigma$ coordinate with stretching [1]. The $\mathrm{u}$ - and v-component velocity is solved explicitly and the $w$-component is from the continuity equation. The grids are re-gridded as the ice geometry changes in response to precipitation, surface melt, and flow divergence/convergence. To effectively reduce numerical noises on flow, an Asselin [43] time filter with coefficient of 0.15 is applied. Using the full NavierStokes equation for ice involves a special time stepping scheme that is adaptive before a balance is reached.

SEGMENT-ice has an adjoint based four dimensional variational data assimilation system (4D-Var). Except the adjoint code [44, 45], which is designed strictly corresponding to the forward ice model component, other com- 
ponents such as optimization and adjoint code verification are inherited from Ren [46]. This companion data assimilation system optimally estimates the granular layer properties, constrained by the present ice sheet flow field, thermal structure and geometry (Figure 8).

\section{Results}

The following two subsections detail the verification of the ice dynamic model using idealized bed and thickness profiles, or verification against locations with observed temperature profiles. Finally, the model is applied to the GrIS.

\subsection{The effects of a basal granular layer}

As mentioned above, one salient feature of the model is the presence of a granular layer between the bedrock and the ice. To investigate the effects of this granular layer on the flow field, a sensitivity experiment is performed assuming an idealized geometry: ice of $-10^{\circ} \mathrm{C}$ and $30 \mathrm{~m}$ uniform thickness resting on a slope of 2 degrees steepness, 45 degree aspect (facing northeast), and of infinite length and width. Figure 1 compares the u-component velocity profiles under granular and non-granular basal conditions. For granular conditions the following parameters are used: a $2 \mathrm{~m}$ deep granular layer, effective radius of $10 \mathrm{~cm}$, density of $2.7 \times 10^{3} \mathrm{~kg} \mathrm{~m}^{-3}$, and dry repose angle of 30 degrees (Figure 1). For this simple geometry configuration, the effect of the granular layer is simply a shift of the overlying ice speed. Thus, above the granular layer, ice speed at every depth is larger than in cases without a granular basal layer by about $2.4 \times 10^{-6} \mathrm{~m} \mathrm{~s}^{-1}$. Because the granular viscosity is less dependent on the existing strain rate, the velocity profile within the granular layer (Figure 1) resembles dilatants material. The maximum reachable flow speed at the top of the granular layer grows nonlinearly with the granular layer depth. Because the maximum reachable speed depends exponentially on granular layer depth, it is possible to retrieve the granular depth by examining the flow field deviation from cases with no-slip basal conditions. The velocity profile within the granular layer can also be pseudoplastic, as effective grain size gets smaller. For real DEM and thickness profiles, the existence of a pseudoplastic or dilatant granular layer can significantly affect the flow divergence/convergence field and hence the mass balance (Figure 2). Increased basal sliding significantly reduces resistive force and may trigger an ice outspread (Figure 2B). This stage ( $B$ in Figure 2) signifies a lowering of the mass toward lower elevations and a thinning of the upper stream ice. The outspread ice is clearly out of balance, even with the current climate, so will melt away quickly. The melt water helps wash away part of the sediments, lowers the snout and sends the ice-sediment interface slope farther away from the supercooling threshould [20]. This makes the basal drainage system more efficient and encourages further erosion and sediment production. Ice outspread also helps remove silt because more concentrated drainage flows from encapsulated subglacial streams increases the bedload transport capacity. Compared with Stage A (Figure 2), the snout is now thinner. In a warming climate, this positive feedback loop continues and signifies an enhanced mass loss rate.

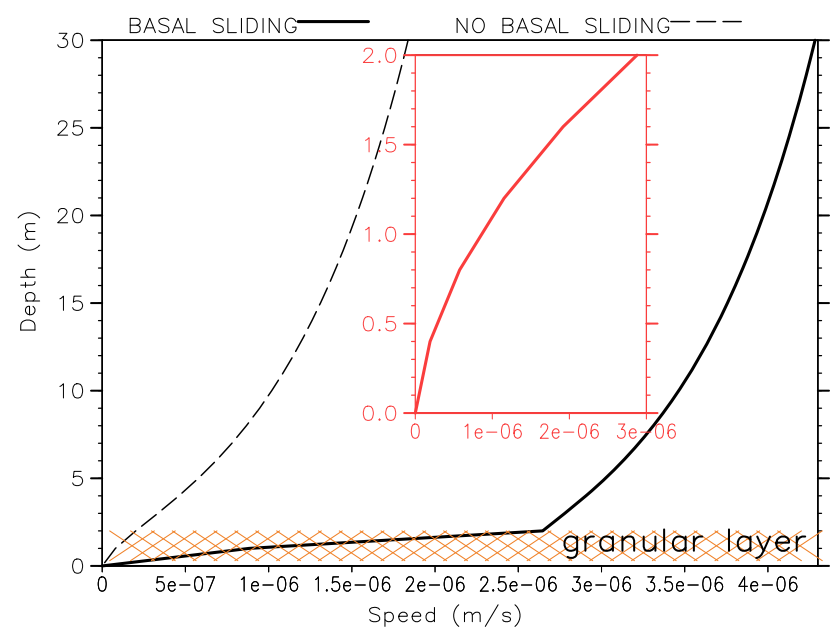

Figure 1. Flow speed (u-component velocity magnitude) profile for an idealized geometry: $-10^{\circ} \mathrm{C}$ ice of uniform thickness $(30 \mathrm{~m})$ resting on a slope of 2 degrees, at a 45 degree aspect (facing due northeast), and infinite length and width. An ice sheet with an underlain granular layer of $2 \mathrm{~m}$ deep, with grain effective radius $10 \mathrm{~cm}$, density of $2.7 \times 10^{3} \mathrm{~kg} \mathrm{~m}^{-3}$, and 30 degree dry repose angle (hatched) is compared to an ice sheet without a granular base. Free-of-stress upper boundary conditions are applied. The inset is a close-up of the velocity profile within the granular basal layer.

\subsection{Verification of the temperature compo- nent}

Knowing the temperature within the ice sheet is vital for ice sheet modelling. Unfortunately, due to the paucity of direct ice temperature measurements, it is hard to directly verify the temperature equation. The frozen soil temperature measurement is known for the year 2000 at Madoi (35.598 $\left.\mathrm{N}, 99.22^{\circ} \mathrm{E} ; 4500 \mathrm{~m} \mathrm{ASL}\right)$, Qinghai, China. Using the NCEP/NCAR atmospheric parameters the model is continuously integrated for 40 years for the region (19612000). Figure 3 shows the temperature evolution at this station, with the corresponding monthly soil temperature 

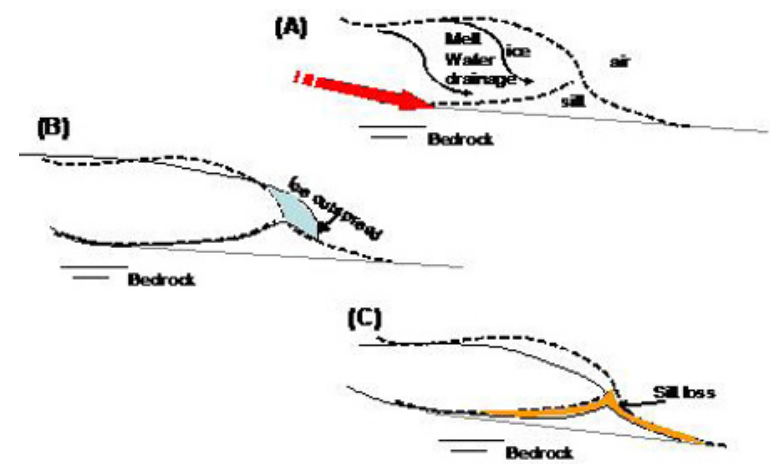

Figure 2. Cartoon illustrations of three stages of a mountain glacier snout movement, showing the influence of basal sliding on glacier mass loss. Dashed lines are the initial boundaries between air, ice and the granular silt. Solid lines are these boundaries at later stages. Stage $(A)$ shows the normal development of a moraine shoal. Increased basal sliding significantly reduces resistive force and may trigger an ice outspread as shown in (B). Stage (B) signifies a lowering of the mass toward lower elevations and a thinning of the upper stream ice. The outspread ice is clearly out of balance even with the current climate. Thus, this part will melt away quickly. The melt water helps wash away part of the sediments, lowers the snout and sends the ice-sediment interface slope farther away from the supercooling threshold (C). This makes the basal drainage system more efficient and encourages further erosion and sediment accumulation. Ice outspread also helps remove the silt because the more concentrated drainage flow from encapsulated subglacial streams increases the bedload transport capacity. Compared with Stage $(A)$, the snout is now thinner. In a warming climate, this positive feedback loop continues and the terminus retreats. For glaciers extending to sea level waters, Stage (C) may not be visible and similarly, for many valley glaciers, stage (B) may be only a conceptual stage.

observations at 5 and $40 \mathrm{~cm}$ respectively. The observed and simulated soil temperatures at the two depths are in agreement for the whole year. The presence of snow cover also agrees well with in situ records.

\subsection{Applications to the GrlS}

For verification against the observed changes of the GrIS during the past decade, the NCEP/NCAR 60-year reanalysis atmospheric parameters are used to force the ice model. The modelled present (2000) surface velocity field, the summer maximum melt area extent (1979-207) and the whole mass loss rate of the GrlS (2003-2008) are examined and compared with corresponding remote sensing measurements.

Within each ice sector (following the convention of Zwally and Giovinetto [47] henceforth), the flow speed increases from the top toward the grounding line. The flow reduces a little bit near the grounding line but cannot be seen on

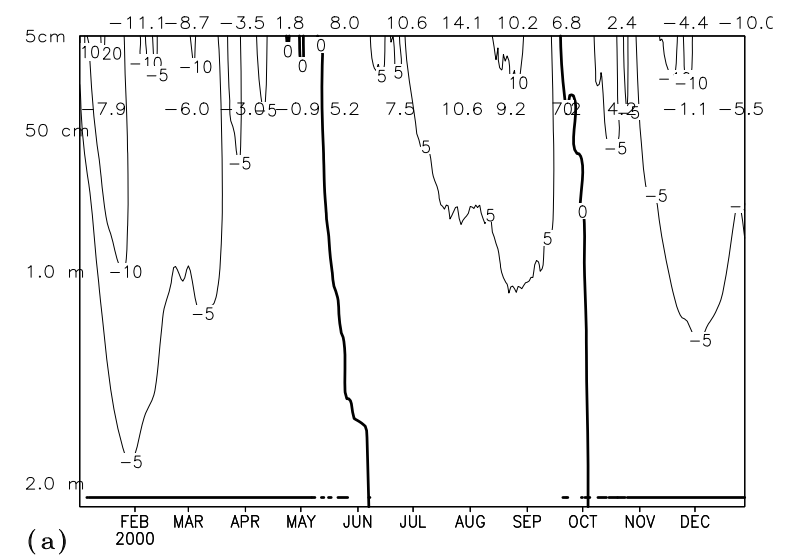

Figure 3. Modelled and observed soil temperature variations over the year 2000 at the Madoi site. Contour lines are model simulated soil temperatures and the brown numbers are observed monthly mean soil temperatures at 5 and $40 \mathrm{~cm}$ respectively. Model simulations are on a daily time scale. The near bottom horizontal red bar shows the period with modelled snow cover.

the plot because the flow field is thinned (output every 4 grids) for clarity. Figure 4 shows the modelled surface velocity (composed from $u$ and $v$ components only) fields for the year 2000, over lain by the balance speed (which could be compared with the laser measured vector velocity when seaRISE posts the data). Although the general pattern of correspondence is acceptable, our flow magnitude is generally smaller than the balance velocity. For the north-east Greenland ice stream (in Region II) and the Jacobshavn Isbræ (the narrow convergent region along the $68^{\circ} \mathrm{N}$ parallel in Region V), our modelled year 2000 surface velocity is close to the ERS-1 satellite observed large flow features [48]. The concentrated ice flow of the Jacobshavn Isbræ results mainly from the ice dynamics rising from bed geometry and the ice thickness profile. The formation of the north-east Greenland ice stream is also primarily due to bedrock geomorphology and ice geometry, and to a lesser degree of importance to geothermal heat flux from the bottom. Region by region analysis indicate that, by the year 2060, the largest changes in the flow fields will be over the northeast (ice sector II) and the southern tip. For ice sector II, modelled surface velocity at the year 2000 reproduces all the primary features of the observed surface velocity [49]. A cautionary note is that the ice-flow velocity in the narrow, fast-moving outlets should not be compared with the model results because the flow speeds are nearly depth-independent, caused by the stress discontinuity and not resolvable in a $5 \mathrm{~km}$ spatial resolution. 

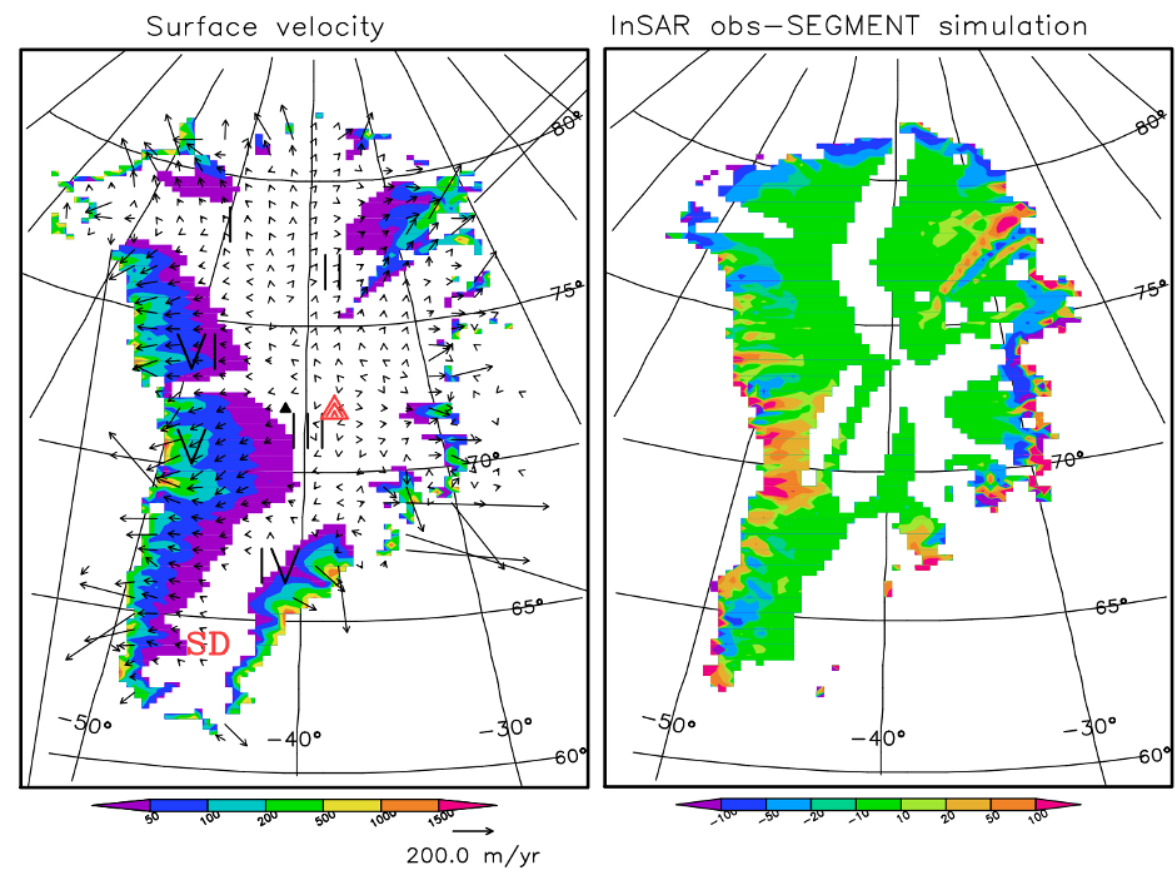

Figure 4. Surface velocity fields for the year 2000, overlain by the observed balance velocity (http://websrv.cs.umt.edu/isis/index.php/Present_Day_Greenland). Ice sectors are clearly identifiable from flow patterns. The minimum speeds are seen around Summit $(\mathbf{\Lambda})$ and the top of the smaller southern dome (SD).

The monthly integration time-step and the vertical stretching scheme allow for the estimation of the summer maximum surface melt extent (SME), a sensitive warming index and useful representation of the ablation zone's temporal variability. Microwave measurements obtain a good estimation of the GrIS surface melt extent and duration because the brightness temperature and the normalized microwave-radar backscatter coefficient are both sensitive to liquid water present in snow [50]. The seasonal surface melt extent on the GrIS has been observed by satellites since 1979 and shows an increasing trend (see Figs. 2a and b, Chapter 6 in ACIA 2005). Warming is central to the expansion of the SME. Fausto et al. [51]used a positive degree day method and successfully simulated the surface melt extent of the same observational dataset. They found that the definition of remote sensed melt area includes both the melt snow zone and runoff zone instead of only the latter. Thus, the 'near-surface forcing criteria' for surface melting is stipulated as a $2 \mathrm{~m}$ air temperature greater than $-5^{\circ} \mathrm{C}$ and net radiation larger than $140 \mathrm{~W} \mathrm{~m}^{-2}$. Defining these criteria is necessary because the melt water depth generally is only a small fraction of the top layer of the model depth. This is especially true for the melt snow zone, where the depth of the top model layer is more than $100 \mathrm{~m}$ in the model terrain. It is not correct that the (thick) surface layer temperature uniformly reaches $0^{\circ} \mathrm{C}$ as a criterion for surface melt. The near-surface forcing criteria ans a surface layer temperature close to $-0.5^{\circ} \mathrm{C}$ are needed to determine if a grid point is in melt state.

The model is spun-up using CCSM provided pre-industrial and 20C3M atmospheric conditions. The CCSM data is replaced with the NCEP/NCAR re-analysis precipitation, temperature and radiative fluxes for the segment covering 1948 to present. Using these above criteria, the modelled SME from 1979 to 2006 (Figure 5) compares well with the cross-polarized gradient ratio method [10] observed melt area in terms of annual variabilities. For example, the relative maxima in years 1998-99, 2002, 2005 and 2007 are all successfully simulated. The remotely sensed observed surface melt extent is processed from the National Snow and Ice Data Center (NSIDC) archive of brightness temperature in a $25 \times 25 \mathrm{~km}$ grid on a polar stereographic projection [52]. At this resolution, the total area for the ice sheet is $\sim 1.76 \times 10^{6} \mathrm{~km}^{2}$, close to what the model represents. Integral over pixels that have at least one day with melt, yields the total annual melt area. The model shows this phenomenon on a monthly time scale. To compare the data, the maximum extent of melt for each year is composed in an annual time series. A high correlation of 0.88 exists between this time series and the observed 1979-2007 melt area. In the 30-year model simulation 
series, the surface melt exhibited large inter-annual and decadal variability, with significant recent melt episodes during the years 2002, 2005 and 2007.

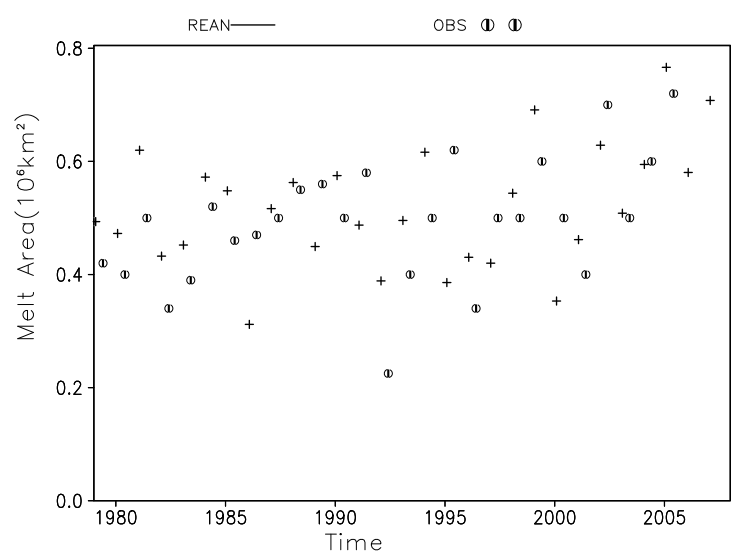

Figure 5. Observed (circular with vertical bar markers) and simulated (cross markers) maximum melt surface area extent. Observations are adapted from the annual melt extent data (NSIDC, http://nsidc.org/). This data is derived from passive microwave satellite brightness temperature characteristics using the cross-polarized gradient ratio (XPGR) of Abdalati and Steffen [10]. The model predicted extent during the years 1979 and 2008 are driven by NCEP/NCAR re-analysis atmospheric conditions.

Time-variable gravity measurements from the Gravity Recovery and Climate Experiment (GRACE) satellite mission can be used to estimate ice mass changes over Greenland [53]. This study has accumulated 598 gravity anomaly maps (covering the period of April 2002 to May 2007) from the GRACE project. The GRACE measured total mass change is compared with model simulations driven by NCEP/NCAR provided meteorological parameters (Figure 6). The model simulation shows a larger seasonal variability than GRACE. Both show significant melt in the years 2002 and 2007, in accordance with recent observational studies (e.g., [7]). The model also indicates 2005 is a year with significant mass loss. The GRACE curve shows a spike in the summer ablation period of 2004 that is not supported by physical mechanisms. We think the data is aliased during this period. If the aliased signal is corrected, the model simulation and GRACE measurements agree well in the annual changes in GrlS total mass (i.e., 2005 is also a year of strong mass loss) for the following years. The modelled spike in early 2006 is also confirmed by a GrlS mass balance survey (Son Nghiem of JPL, personal communication, August 2009), which shows extraordinary strong accumulation during the winter 2005 to spring 2006 accumulation season. The GRACE gives a smoother signal than the model, as expected. Both model and GRACE observations have similar mass loss rate: about $-147 \mathrm{~km}^{3} \mathrm{yr}^{-1}$ over the $2002-2008$ period.

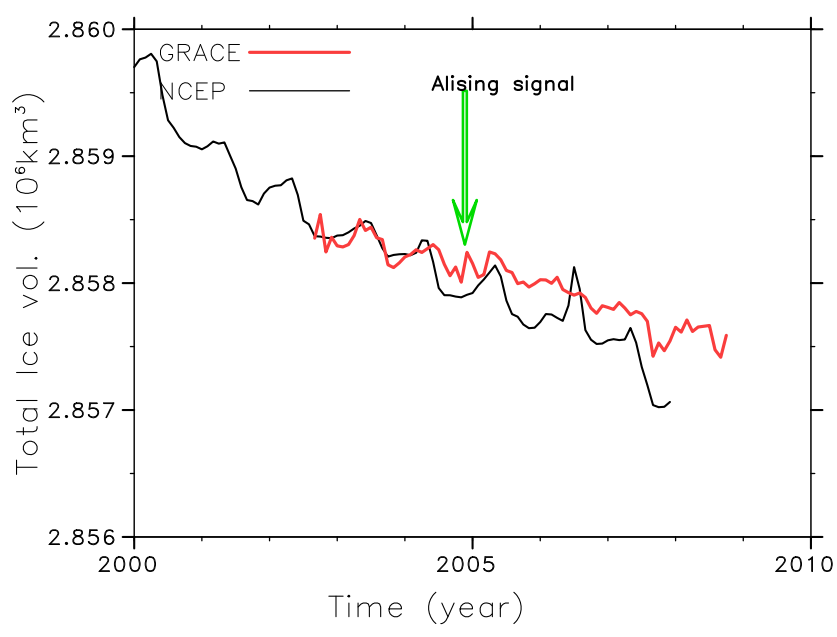

Figure 6. Total ice volume changes of the Greenland ice sheet for the past decade. Comparisons are between model simulations using NCEP/NCAR re-analysis meteorological conditions (black line) and GRACE measurements (red line).

Using a linear fit to the trend, a mass change rate map is obtained (from the 598 snapshots). Mass change rate maps corresponding to the same period also are produced by the ice dynamics model, using the atmospheric forcing series from CCSM3 and MIROC3.2 respectively. The GRACE measurements give a smooth picture of mass loss of various degrees centred on the southeast (as high as $-8 \mathrm{~cm} \mathrm{yr}^{-1}$ at the crossing of $68^{\circ} \mathrm{N}$ and $39^{\circ} \mathrm{W}$ ). Earlier release covering GRACE measurements up to November 2005 indicate a north mass loss region (point B on Fig. 2 of Chen et al., [53]). This signal disappeared as more new data is included (J. Chen, personal communication). This further confirms that the year 2004 spike in the total mass loss curve is a spurious signal. The CCSM3 one indicates the primary mass deficit is around the southern dome and the southeast section facing the Denmark Strait (which is close to the model simulation forced by the re-analysis data), whereas the MIROC3.2 indicates a stronger rate and the primary mass loss is along the west edge facing Baffin Bay. The apparent discrepancy among the three indicates that GCM-provided atmospheric conditions are insufficient to discern annual to decadal time scale fluctuations over the region.

Using CCSM3 provided atmospheric parameters under a strong emission scenario (SRES A2), total ice volume changes are compared under three different basal conditions (Figure 7): no-slip, Weertman-type sliding and granular-type basal sliding. The effects of basal sliding are small before 2030. Then, as temperatures continue to 
warm, the basal sliding mechanism becomes significant, especially beneath the southern tip and the north east ice stream, and signifies a more rapid mass-shed. The differences between the two basal sliding schemes are insignificant prior to 2060. After 2060, the granular basal sliding scheme signifies a far more efficient mechanism for mass-shed, in accordance with the explanation of Bueler and Brown [29]. Using MIROC3.2 output as forcing gives qualitatively the same results.

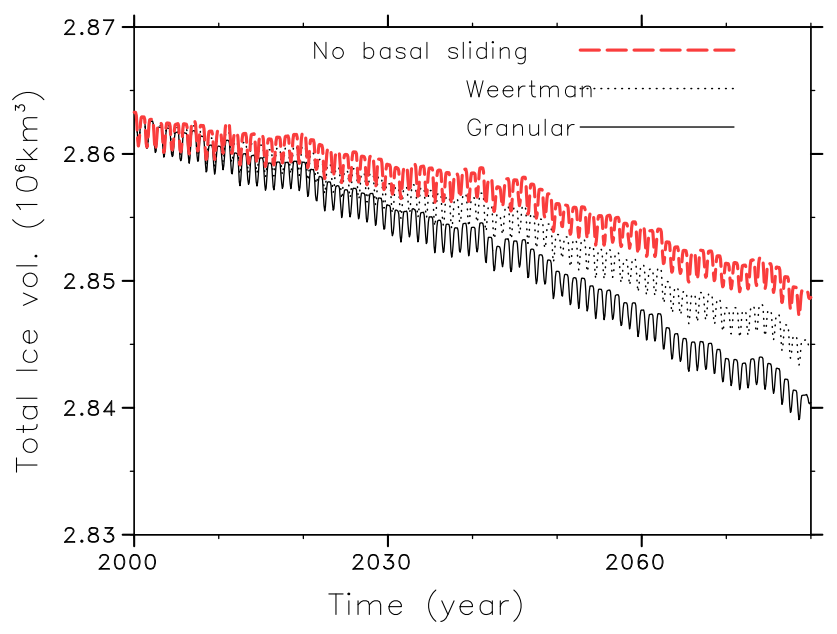

Figure 7. Net mass changes of the Greenland ice sheet for the $21^{\text {st }}$ century. Comparisons between two basal sliding schemes: Weertman and a granular type of basal sliding. Atmospheric forcing parameters provided by CCSM3 under SRES A2 scenario.

With the $5 \mathrm{~km}$ resolution of the model, no stress discontinuities exist in the ice sectors. However, it cannot be argued that the response of GrIS to climate warming must be gradual, because the distribution of crevasses [33] has not been implemented directly in the model. The implementation of this and the viscosity enhancement by re-fabricating [54] is a future aim. As stated above, the model uses the SICOPOLIS approach for temperate ice. The enthalpy method is the best means to uniformly treat the cold and temperate ice (e.g., Aschwanden and Blatter, [55]). It shows advantages for the finite element solver. The implementation of this concept into mechanical and thermodynamically tightly coupled systems would be rewarding.

\section{Conclusion}

Several recent surveys, using micro-wave remote sensing, indicate dramatic changes in GrIS surface melt, surface flow field and total mass loss during the past decade.
Because the melt water is an important source for sea level rise, it is desirable to predict the future state of the GrIS. In this study, a new ice dynamics model with granular basal sliding is introduced, and driven using CGCM model outputs and NCEP/NCAR re-analysis atmospheric parameters. The re-analysis driven experiment compares favourably with the mass loss rate derived from the Gravity Recovery and Climate Experiment (GRACE) and the XPGR observed surface melt area over the past decade.

Ice sheet models conventionally assume a local force balance, under the assumption that under near-steady state conditions, the climatically controlled surface balance (snowfall minus melt) controls the geometry of an ice mass, and changes in thickness are forced primarily by changes in surface mass balance. In contrast, our results indicate that, changes in ice velocity can be forced by changes in sub-glacial mechanics in addition to upper boundary thermal regime changes. This conclusion is especially relevant for a future warming climate. This also agrees with of the study of Meier et al. [56] on the Columbia glacier of Alaska.

The most significant changes in the flow pattern of the GrlS occur at the ice sheet margins, where fast-flowing ice streams discharge large amounts of ice into the ocean. For example, Rignot and Kanagaratnam [11] indicate that the Jacobshavn-Isbræ glacier, with an approximate width of only $5 \mathrm{~km}$ contributes up to $7-10 \%$ of the total ice discharge from the GrlS. Because of their comparably large aspect ratios, ice streams and the surrounding transition zones are the areas where a full Stokes model is expected to be superior to shallow models, but only if the mesh size is small enough. The present employed grid size of $5 \mathrm{~km}$ is not able to capture the geometry of these ice streams adequately. Future efforts would be directed towards obtaining high resolution ice digital elevation and thicknees data of sub-kilometre resolution and making highresolution regional simulations of the GrIS.

\section{Acknowledgements}

This work is supported by the Gary Comer Science Foundation. We thank Professors R. Alley for providing the GISP2 borehole data, R. Greve for offering the SICOPOLIS model code, and Van der Veen for providing the force balance model code. The first author also thanks Dr. Jezek for his insightful comments on the possible importance of the advection and inertial terms for the ice flow model. Ms. Otsu helped provided the NASA-JPL images of observed surface velocity. Ms. Molly from NSIDC provided technical assistance in using the remote sensing data. We acknowledge Ms. Jun Wang at NCEP for providing the re- 
analysis data. Transient climate simulations under SRES A1B were obtained from the PCMDI/CMIP project.

\section{Appendix}

We propose a new ice dynamics model based on the Navier-Stokes formula. In standard notation, the mass conservation equation is

$$
\nabla \cdot \vec{V}=0
$$

and the momentum conservation equation is

$$
\rho\left[\frac{\partial \vec{V}}{\partial t}+\nabla \cdot(\vec{V} \otimes \vec{V})\right]=\nabla \cdot \sigma+F
$$

where $\rho$ is density, $\vec{V}$ is velocity vector, $\sigma$ is internal stress tensor, and $F$ is the body force (e.g. gravity $\rho \vec{g}$ ). Instead of the standard decomposition of the full stress tensor $\sigma$ into static and dynamic stress parts, here we split it into lithostatic $(L)$ and resistive $(R)$ parts $[24,57]$ : $\sigma_{i j}=R_{i j}+\delta_{i j} L$ where $R_{i j}$ denotes the components of the resistive tensor, and $\delta$ is the Kronecker operator.

As a non-Newtonian fluid, polycrystalline ice has a shearthinning rheology in which the strain-rate is proportional to the applied deviatoric stress raised to an exponent [53]. This proportionality is temperature dependent $[35,58]$ and here it follows the parameterization in Hooke [61]. For the Greenland ice domain, this parameterization gives a viscosity range of $4 \times 10^{13}-1.1 \times 10^{15} \mathrm{~Pa} \cdot \mathrm{s}$. From several possibilities [35], Glen's constitutive relationship is choosen because it has proven to be fairly accurate for studying the large-scale flow characteristics of real glaciers [53] and therefore should provide good estimates of total mass loss and overall changes in the surface elevations. Applying the constitutive relationship reduces the unknowns in Equation 3 to the three velocity components ( $u, v$ and $w)$. Based on conservation of mass, momentum and energy, originally non-glaciated grids can be glaciated and vice-versa.

The movement of glacial ice is achieved by a combination of plastic flow, sliding, and the deformation of underlying basal sediments. Pressure melted water plays an important role in each of these processes. Weertman [31] showed how the rate of ice sliding at the local pressure melting temperature (PMP) depends on scales of roughness elements on the glacier bed. However, the original form of Weertman's law does not fit into the framework of field dimension sliding [60], nor does it treat the frictional stresses exerted by entrained sediment particles, which are important contributors to the overall shear stress at the bed $[19,60]$. The liquid-like layer separating the ice from the bedrock exists even for glaciers far below the bulk PMP at their base [61]. This concept has been adopted by modellers and has been observed in the field $[62,63]$. The 'grade-glacier' theory [64] generalizes silt production and transportation as an integrated component of the ice erosion on the glacier base. It shows that climate fluctuations, by modifying the ice surface slope, can affect sediment transport and erosion patterns. This theory directly motivated the current study because a warming climate may flatten the marginal area of the fast glaciers surrounding the Greenland ice sheet, and therefore increase the deposition of granular sediments.

We use the following thermal equation [22]:

$$
\rho c\left(\frac{\partial T}{\partial t}+(\vec{V} \cdot \nabla) T\right)=k \Delta T+\frac{2}{v} \cdot \sigma_{e f f}^{2}
$$

Where $c$ is heat capacity $(\mathrm{J} / \mathrm{kg} / \mathrm{K}), T$ is temperature $(\mathrm{K})$, $\kappa$ is thermal conductivity $\left(\mathrm{W} \mathrm{K}^{-1} \mathrm{~m}^{-1}\right)$, and $\sigma_{\text {eff }}$ is effective stress ( $\mathrm{Pa})$. The last term is 'strain heating', or the conversion of work done by gravity into heat used to heat the sliding material or cause phase change.

The dynamic (Equation 2) and thermodynamic (Equation 3) equations are coupled. The upper boundary condition for Equation 3 is that of free-stress. The zerovelocity-gradient is applied as a lateral boundary condition. The boundary conditions for Equation 4 are a surface temperature at the top of each grid $\left(\left.T\right|_{z=z t}=T_{s}(x, y)\right)$ and a geothermal flux to the base of the lithosphere layer $\left(\left.k \frac{\partial T}{\partial z}\right|_{z=z b}=G_{0}\right.$, here $G_{0}$ is geothermal heat flux in $\mathrm{W} \mathrm{m}^{-2}$ ). The ice model is schematically represented in Figure 8.

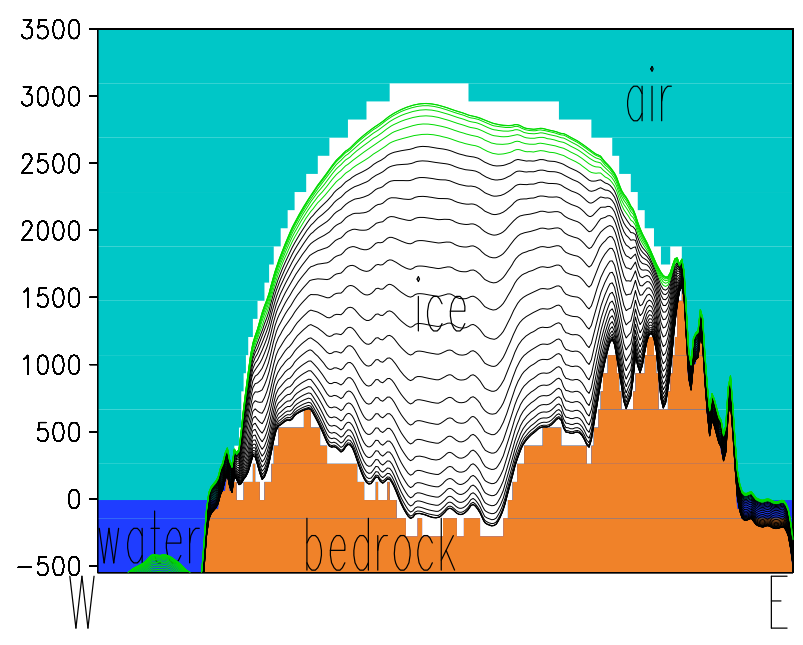

Figure 8. A schematic of the ice dynamic model (SEGMENT-ice). 


\section{References}

[1] Greve R., Blatter H., Dynamics of Ice Sheets and Glaciers. Series: Advances in Geophysical and Environmental Mechanics and Mathematics, SpringerVerlag Berlin Heidenberg, 2009

[2] Yin J., Schlesinger M., Stouffer R., Model projections of rapid sea-level rise on the northeast coast of the United States, Nature, 2009, 2, 262-266

[3] Alley R., Ice-core evidence of abrupt climate changes, PNAS (please expand), 2000, 97, 1331-1334

[4] Thomas R., PARCA Investigators 1, Program for arctic regional climate assessment (PARCA): Goal, key findings, and future directions, J. Geophys. Res. 2001, 06, 33691-33705

[5] Steffen K., Box J., Surface climatology of the Greenland ice sheet: Greenland climate network 19951999, J. Geophys. Res., 2001, 106, 33951-33964

[6] Bamber, J., Ekholm S., Krabill W., A New, highresolution digital elevation model of Greenland fully validated with airborne laser altimeter data, J. Geophys. Res., 2001, 106, 6733-6745

[7] Mote T. L., Greenland surface melt trends 1973-2007: Evidence of a large increase in 2007, Geophys. Res. Lett., 2007, 34, L22507, doi:10.1029/2007GL031976

[8] Alley R., The Younger Dryas cold interval as viewed from central Greenland, Quaternary Sci. Revi., 2000, 19, 213-226

[9] Krabill W., Abdalati W., Frederick E., Manizade S., Martin C., Sonntag J., Swift R., Thomas R. et al., Greenland ice sheet: High-elevation balance and peripheral thinning, Science, 2000, 289, 428-430

[10] Abdalati W., Steffen K., Snowmelt on the Greenland Ice Sheet as derived from passive microwave satellite data, J. Climate, 1997, 10, 165-175

[11] Rignot E., Kanagaratnam P., Changes in the velocity structure of the Greenland ice sheet, Science, 2006, 311, 986-990

[12] Hansen J., Sato M., Ruedy R., Lo K., Lea D., MedinaElizade M., Global temperature change, P. Natl.Acad. Sci. USA, 2006, 103, 14288-14293

[13] Solomon S., Qin D., Manning M., Chen Z., Marquis M., Averyt K.B., Tignor M., Miller H.L. (Eds.), Contribution of Working Group I to the Fourth Assessment Report of the Intergovernmental Panel on Climate Change, 2007, Cambridge University Press, Cambridge and New York, 2007

[14] Ren D., Karoly D., M. Leslie L., Mountain glacier melting rate for the period 2001-2030 estimated from three CGCM simulations for the Greater Himalayas. J. Appl. Meteorol. Climatol., 2007, 46, 890-899
[15] Thompson L., Yao T., Mosley-Thompson E., Davis M., Henderson K., Lin P., A high resolution millennial record of the south Asian monsoon from Himalayan ice cores, Science, 2000, 289, 1916-1919

[16] Alley R., In search of ice-stream sticky spots, J. Glaciol., 1993, 39, 447-454

[17] Jacka T., Recommendations from the SCAR Ice Sheet Mass Balance and Sea Level (ISMASS) Workshop. American Geophysical Union, Spring Meeting 2002, abstract U42A-01

[18] Jop P., Forterre Y., Pouliquen O., A constitutive law for dense granular flows, Nature, 2006, 441, 727-730

[19] MacAyeal D., Irregular oscillations of the west Antarctic ice sheet, Nature, 1992, 359, 29-32

[20] Alley R., Dupont T., Parizek B., Anandakrishnan S., Lawson D., Larson G., Evenson E., Outburst flooding and initiation of ice-stream surges in response to climatic cooling: A hypothesis, Geomorphology, 2005, 75, 76-89

[21] Greve R., On the response of the Greenland ice sheet to greenhouse climate change, J. Climatic Change, 2000, 46, 289-303

[22] Greve R., Relation of measured basal temperatures and the spatial distribution of the geothermal heat flux for the Greenland ice sheet, Annals of Glaciology, 2005, 42, 424-432

[23] Cuffey K., Clow G., Alley R., Stuiver M., Waddington E., Saltus R., Large arctic temperature change at the Wisconsin-Holocene glacial transition, Science, 1995, 270, 455-458

[24] Pollack H., Hurter S., Johnson J., Heat flow from the Earth's interior: analysis of the global data set, Rev. Geophys., 1993, 31, 267-280

[25] Collins W., Bitz C., Blackmon M., Bonan G., Bretherton C., Carton J., Chang P., Doney S., et al., The community climate system model: CCSM3, J. Climate, 2006, 19, 2122-2143

[26] Van der Veen C., Whillans I., Force budget: I. Theory and numerical methods, J. Glaciology, 1989, 35, 53-60

[27] Ren D., Leslie L., Karoly D., Landslide risk analysis using a new constitutive relationship for granular flow, Earth Interact., 2008, 12, 1-16

[28] Zwinger T., Greve R., Gagliardini O., Shiraiwa T., Lyly M., A full Stokesflow thermo-mechanical model for firn and ice applied to Gorshkov crater glacier, Kamchatka, Ann. Glaciol., 2007, 45, 29-37

[29] Bueler E., Brown J., Shallow shelf approximation as a "sliding law" in a thermaomechanically coupled ice sheet model, J. Geophys. Res., 2009, 114, F03008

[30] Engelhardt H., Kamb B., Basal sliding of Ice Stream B, West Antarctica, J. Glaciol., 1998, 44, 223-230

[31] Weertman J., Creep deformation of ice, Annu. Rev. of 
Earth. Pl. Sc., 1983, 11, 215-240

[32] Bindschadler R., The importance of pressuruized subglacial water in seperation and sliding at the glacier bed, J. Glaciol., 1983, 29, 3-19

[33] Zwally H., Abdalati W., Herring T., Larson K., Saba J., Steffen K., Surface melt-induced acceleration of Greenland ice-sheet flow, Science, 2002, 297, 218222

[34] Glen J., The creep of polycrystalline ice, Proc. Roy. Soc. Lond. A, 1955, 228, 519-538

[35] Goldsby D., Kohlstedt D., Superplastic deformation of ice: experimental observations, J. Geophys. Res., 2001, 106, 11017-11030

[36] Durham W.B., Kirby S.H., Stern L.A., Effects of dispersed particulates on the rheology of water ice at planetary conditions, J. Geophys. Res., 1992, 97, 20883-20897

[37] Smith E., Crosson W., Cooper H., Weng H., Estimation of surface heat and moisture fluxes over a prairie grassland. Part III: Design of a hybrid physical/remote sensing biosphere model, J. Geophys. Res., 1993, 98, 4951-4978

[38] Crosson W., Laymon C., Inguva R., Schamschula M., Assimilating remote sensing data in a surface flux-soil moisture model, Hydrol. Proc., 2002, 16, 1645-1662

[39] Benson C., Stratigraphic studies in the snow and firn of the Greenland ice sheet. Snow, Ice and Permafrost Research Establishment (SIPRE), Research Report 70, U.S. Army Cold Regions Research and Engineering Laboratory, Hanover, New Hampshire, 1962

[40] Ohmura A., Wild M., Bengtsson L., A possible change in mass balance of Greenland and Antarctica ice sheets in the coming century, J. Climate, 1996, 9, 2124-2135

[41] Oerlemans J., Glaciers and Climate Change, A.A. Balkema Publishers, Lisse, 2001

[42] Peng G., Leslie L., Shao Y., Environmental modeling and prediction, Springer Verlag Berlin Heidenberg New York, 2002

[43] Asselin R., Frequency filter for time integrations, Mon. Wea. Rev., 1972, 100, 487-490

[44] Ren D., Adjoint retrieval of prognostic land surface model variables for an NWP model: Assimilation of ground surface temperature, Cent. Eur. J. Geosc., 2010, 2, 83-102

[45] Schoof C., A variational approach to ice stream flow, J. Fluid Mech., 2006, 556, 227-251

[46] Ren D., 4D-Var retrieval of prognostic land surface model variables, PhD Thesis., University of Oklahoma, Norman, Oklahoma, 2004

[47] Zwally H., Giovinetto M., Balance mass flux and ice velocity across the equilibrium line in grainage systems of Greenland, J. Geophys. Res., 2001, 106, 33717-33728

[48] Fahnestock M., Bindschadler R., Kwok R., Jezek K., Greenland ice sheet surface properties and ice dynamics from ERS-1 SAR imagery, Science, 1993, 262, 1530-1534

[49] Joughin I., Fahnestock M., MacAyeal D., Bamber J., Gogineni P., Observation and analysis of ice flow in the largest Greenland ice stream, J. Geophys. Res., 2001, 106, 34021-34034

[50] Ashcraft I.S., Long D., Comparison of methods for melt detection over Greenland using active and passive microwave measurements, Internat. J. Remote Sens., 2006, 27, 2469-2488

[51] Fausto R., Ahlstrom A., Van As D., Boggild C., Johnsen S., A new present-day temperature parameterization for Greenland, J. Glaciology, 2009, 55, 95-105

[52] Maslanik J., Stroeve J., DMSP SSM/I daily polar gridded brightness temperature, 1987-2007, digital media, National Snow and Ice Data Centre Boulder, Colorado, 2007

[53] Chen J., Wilson C., Tapley B., Satellite gravity measurements confirm accelerated melting of Greenland ice sheet, Science, 2006, 313, 1958-1960

[54] Wang W., Warner R., Modelling of anisotropic ice flow in Law Dome, East Antarctica, Ann. Glaciol., 1999, 29, 184-190

[55] Aschwanden A., Blatter H., Mathematical modelling and numerical simulation of polythermal glaciers, J. Geophys. Res., 2009, 114, F01027

[56] Meier M., Dyurgerov M., Rick U., O’Neel S., Pfeffer W., Anderson R., Anderson S., Glazovsky A., Glaciers Dominate Eustatic Sea-Level Rise in the 21st Century, Science, 2007, 317, 1064-1067

[57] Van der Veen C., Fundamentals of glacier dynamics, A.A. Balkema, Rotterdam, Netherlands, 1999

[58] Paterson W., The physics of glaciers, Pergamon, New York, 1994

[59] Goldsby D., Kohlstedt D., Superplastic deformation of ice: experimental observations, J. Geophys. Res., 2001, 106, 11017-1103

[60] Hooke R., Iverson N., experimental study of ice flow around a bump: Comparison with theory. Geogr. Ann., 1985, 67A, 187-197

[61] Gilpin R., A model of the "liquid-like" layer between ice and a substrate with applications to wire regelation and particle migration, J. Colloid. Interface Sci., 1979, 68, 235-251

[62] Shreve R., Glacier sliding at subfreezing temperatures, J. Glaciology, 1984, 30, 341-347

[63] Hallet B., Glacial quarrying: a simple theoretical model, Ann. Glaciol, 1996, 22, 1-9 
[64] Alley R., Marotzke J., Nordhaus W.D., Overpeck J.T., Peteet D. M., Pielke R.A. Jr., Pierrehumbert R.T., Rhines P.B. et al., Abrupt Climate Change, Science,2003, 299, 2005-20103 